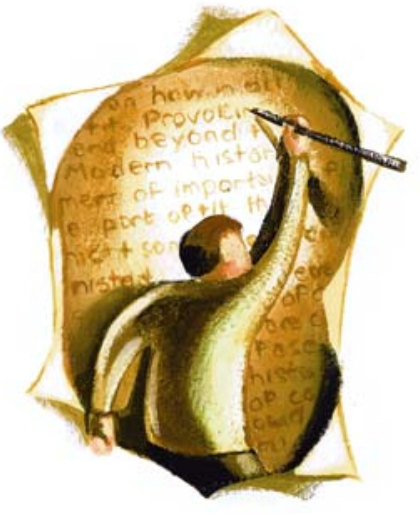

Use of OxyContin by

\section{adolescent students}

Although increases in the nonmedical use of OxyContin (oxycodone) in the United States have been reported recently, ${ }^{1,2}$ few data are available to assess whether such use has diffused into general populations in Canada.

In a school survey of 7726 Ontario students in grades 7 to $12,{ }^{3} \mathrm{I} .3 \%$ of the students $(95 \%$ confidence interval [CI] $0.9 \%$ to $\mathrm{I} .7 \%$ ) reported lifetime use of OxyContin, and $\mathrm{1} .0 \%$ (95\% CI $0.7 \%$ to $\mathrm{I} .5 \%$ ) reported use in the past year. Similar to the situation for other illegal drugs, ${ }^{3}$ the majority $(69 \%)$ of past-year users had used the drug only once or twice. Reported use did not vary significantly by sex or grade but did vary by region, with the highest past-year use occurring among students in Northern Ontario (3.3\%; $95 \%$ CI r. $8 \%$ to $6.1 \%$ ).

To assess whether OxyContin users differ from the users of other illicit drugs, we compared the drug-use profiles of to5 lifetime OxyContin users and 909 users of illicit drugs other than cannabis and OxyContin. The results suggested that OxyContin is merely an addition to the repertoire of drugs used by adolescents. Among 13 illicit drugs examined (e.g., cannabis, heroin, methamphetamine, barbiturates, stimulants, tranquilizers, LSD, phencyclidine $[\mathrm{PCP}]$, hallucinogens, cocaine, crack, ecstasy and methylphenidate). OxyContin users were significantly more likely than nonusers to use only 4 of these drugs (heroin, barbiturates, tranquilizers and methylphenidate).
This finding raises the spectre of potential polydrug reactions.

Of course, such data are not without limitations. For example, as for other illicit drugs, we would expect some degree of underreporting of OxyContin use. Also, our question was restricted to OxyContin use and thus did not yield information about the use of oxycodone in general and other opioids.

Still, these data, which constitute one of the first reports of OxyContin use within a general Canadian population, allow 2 important observations. First, at this point, there is no evidence of the diffusion of OxyContin into mainstream adolescent populations. Second, our Ontario estimates are lower than the most comparable ones available from the United States. According to US data for $2005,{ }^{2} \mathrm{I} .8 \%$ of 8 th-graders, $3.2 \%$ of Ioth-graders and $5.5 \%$ of I 2 th-graders reported pastyear use of OxyContin; the corresponding data for Ontario students were $0.7 \%$ ( $95 \% \mathrm{CI} 0.3 \%$ to $\mathrm{r} .6 \%$ ), $0.7 \%$ ( $95 \% \mathrm{CI} 0.3 \%$ to $\mathrm{I} .5 \%$ ) and $\mathrm{I} .4 \%(95 \%$ CI $0.7 \%$ to $2.7 \%$ ).

\section{Edward M. Adlaf \\ Angela Paglia-Boak \\ Bruna Brands \\ Centre for Addiction and \\ Mental Health \\ Toronto, Ont.}

\section{REFERENCES}

I. Sees KL, Di Marino ME, Ruediger NK, et al. Nonmedical use of OxyContin tablets in the United States. J Pain Palliat Care Pharmocather 2005;19 (2):13-23.

2. Johnston LD, O'Malley PM, Bachman JG, et al. Monitoring the future national results on adolescent drug use: overview of key findings, 2005. Bethesda (MD): National Institute on Drug Abuse; 2006.

3. Adlaf EM, Paglia-Boak A. Drug use among Ontario students, 1977-2005: detailed OSDUS findings. Toronto: Centre for Addiction and Mental Health; 2005.

DOI:I0.1503/cmaj.1060037

\section{Questions about Adderall XR}

As reported by Wayne Kondro, ${ }^{1}$ Health Canada's February 2005 decision to withdraw Adderall XR (a mixture of 4 amphetamine salts marketed by Shire Biochem for the treatment of attention deficit hyperactivity disorders [ADHD]) was reversed in August by a 3-member New Drug Committee. Stronger labelling has been recommended, and sudden death, myocardial infarction, cerebrovascular accident and convulsion will be added to the list of adverse drug reactions.

This situation raises a number of disturbing questions. Given that Adderall XR was approved by Health Canada after deaths and other problems had been reported to the US Food and Drug Administration, it must be asked whether Health Canada had those reports when it approved the drug. If so, why did approval go ahead? If not, why did it apparently take more than a year for Health Canada to acquire the reports? There is a lack of evidence that Adderall $\mathrm{XR}$ is clinically superior to other stimulants used to treat ADHD, the New Drug Committee found that higher risks of sudden cardiac death have "not been ruled out due to limitations in the data currently available," ${ }^{2}$ and there is clear evidence of underreporting of serious adverse events. Given these problems, what is the Canadian public to make of the decision to reintroduce Adderall XR?

The reliance on stronger labelling also raises questions. In the United States, stronger labelling for another ADHD drug, pemoline (Cylert), was ineffective in ensuring safe use. ${ }^{3}$ In this type of situation, the precautionary principle - had it been heeded would have provided clear guidance. With no additional health benefits and reasonable suspicion of harm, public health concerns should trump economic interests, yet the New Drug Committee appears to have decided otherwise. To what extent does this reflect the committee's terms of reference and process? The committee met in private and reviewed only data that had been provided by Shire and Health Canada. The committee's mandate appears not to have included issues such as the imprecise diagnosis of ADHD, evidence of overdiagnosis of the condi- 